DEMOGRAPHIC RESEARCH

VOLUME 30, ARTICLE 53, PAGES 1463-1494

PUBLISHED 13 MAY 2014

http://www.demographic-research.org/Volumes/Vol30/53/

DOI: 10.4054/DemRes.2014.30.53

Research Article

Educational differentials in cohort fertility during the fertility transition in South Korea

\title{
Sam Hyun Yoo
}

(c) 2014 Sam Hyun Yoo.

This open-access work is published under the terms of the Creative Commons Attribution NonCommercial License 2.0 Germany, which permits use, reproduction \& distribution in any medium for non-commercial purposes, provided the original author(s) and source are given credit.

See http:// creativecommons.org/licenses/by-nc/2.0/de/ 


\section{Table of Contents}

1 Introduction 1464

2 Educational differentials in fertility over the fertility transition 1465

3 The fertility transition in South Korea 1467

$4 \quad$ Data and methods 1470

4.1 Data and measures 1470

$\begin{array}{lll}4.2 & \text { Methods and strategy } & 1472\end{array}$

$5 \quad$ Results 1473

5.1 Completed fertility and educational fertility differentials 1473

5.2 Was the fertility decline in Korea driven by educational expansion? 1477

5.3 Can a leader-follower model explain the fertility decline in South 1479

Korea?

$6 \quad$ Conclusions and discussion $\quad 1483$

$7 \quad$ Acknowledgements 1486

$\begin{array}{ll}\text { References } & 1487\end{array}$

$\begin{array}{ll}\text { Appendix } & 1493\end{array}$ 


\title{
Educational differentials in cohort fertility during the fertility transition in South Korea
}

\author{
Sam Hyun Yoo ${ }^{1}$
}

\begin{abstract}
BACKGROUND

While there has been a considerable amount of research on the association between women's education and fertility rates, few of these studies have examined the pattern of fertility differentials over the course of the fertility transition. As a country that has experienced a rapid decline in fertility and marked improvements in women's educational attainment over the last several decades, South Korea represents an ideal case for studying this dynamic association.
\end{abstract}

\section{OBJECTIVE}

The aim of the article is to explain the pattern of fertility differentials by level of education and the contribution of the changes in women's educational attainment to the fertility decline during the fertility transition in South Korea.

\section{METHODS}

Drawing upon data from the Korean censuses conducted between 1970 and 2010, I analyze completed cohort fertility for women born between 1926 and 1970 using demographic-decomposition techniques and cohort parity progression ratios by level of education.

\section{RESULTS}

The differences in fertility by educational attainment have gradually declined over the transition, with fertility almost converging at a low level among recent birth cohorts. Fertility in South Korea had been declining in all of the social groups until the subreplacement fertility was reached. The change in women's educational attainment then became an important factor in the further decline in fertility. The trend toward fewer children quickly spread from the most educated to the least educated women throughout the fertility transition.

\footnotetext{
${ }^{1}$ T. Denny Sanford School of Social and Family Dynamics, Arizona State University.

E-Mail: samhyun.yoo@asu.edu.
} 


\section{CONCLUSIONS}

The transformation of fertility behaviors across social strata has been a key element in the Korean fertility transition. Although educational expansion, particularly the introduction of mass education, has contributed to falling fertility in South Korea, the role of education in fertility decline is more pronounced in the diffusion of innovative ideas and behaviors, which reduced fertility differentials across social strata.

\section{Introduction}

Women's education is usually associated with lower fertility at both the population and the individual levels (Bongaarts 2003; Caldwell 1982; Castro Martín 1995; Cochrane 1979; Jeffery and Basu 1996; Jejeebhoy 1995). However, the empirical association between changes in educational levels and changes in fertility rates at the population level is more complex. Educational change is associated with a range of economic and social changes which can alter the link between education and childbearing and/or the intensity of the link. As a result, although rising education generally leads to falling birth rates, the importance of educational trends varies. For instance, compositional change in education levels was found to account for $70 \%$ of the decline in fertility in Brazil between the 1935-1939 and 1951-1953 birth cohorts (Lam and Duryea 1999), but only about one-third of the decline in fertility between 1980 and 2000 in Iran (Abbasi-Shavazi et al. 2008). The impact of educational change likely depends on the starting levels of education and fertility, as well as other contextual factors. Despite the theoretical importance of education as a contributing factor in the fertility transition, there have been relatively few longitudinal studies on education and fertility.

In this article, I use census data from South Korea to analyze changing associations between education and fertility, and look at how compositional changes in education contributed to the decline in fertility across the transition from a high to a lowest-low level. South Korea (hereafter Korea) experienced one of the fastest fertility declines in the world. The Korean total fertility rate was 6.0 in the 1960s, but it had plummeted to sub-replacement levels by 1983 (Statistics Korea 2014). It took Korea less than 25 years to go from a pre-transitional stage to sub-replacement levels of fertility. In England, by contrast, this process took almost 130 years. Over that period, there were marked improvements in women's education. The college entrance rate among female high school graduates was $22.2 \%$ in 1980 , but had reached nearly $80 \%$ by the late 2000 s (Statistics Korea 2010). Among the 1960 birth cohort, the proportion of women who had graduated from high school was negligible; but among the 1970 birth cohort, the share was more than $95 \%$. The combination of a dramatic decline in fertility and a rapid 
increase in women's education makes the country an ideal case for studying this relationship during the fertility transition. Given the general association between fertility and education, we can hypothesize that the expansion of women's education was a major factor that contributed to the rapid transition from high to low fertility rates in Korea.

In this paper, I explore educational differentials in fertility and the changes over the course of the fertility transition in Korea. I briefly review theories on these differences by educational level and describe the Korean fertility transition. In the results section, I first display the trend of educational differentials in completed cohort fertility among women born between 1926 and 1970, and then examine the association between changes in fertility and in the composition of women's educational attainment levels. I also analyze the education-specific pattern of falling fertility over the transition. The key findings and their implications are discussed in the final section. Throughout this paper, I utilize completed cohort fertility to measure fertility instead of the period total fertility rate (TFR), which is often distorted or underestimated in places like Korea, where ages at childbearing change rapidly (Bongaarts and Feeney 1998). This paper contributes to the literature on the association between women's education and fertility, and has implications for population policies in both developing and developed countries.

\section{Educational differentials in fertility over the fertility transition}

Despite the long-standing interest among researchers in the association between education and fertility, few theories on how educational differentials change over time have been offered. Bongaarts (2003) summarized the changes in educational differentials over different stages of the fertility transition, and suggested two theoretical models: (1) the "leader-follower" model and (2) the "permanent difference" model. Cleland (2002) also described the first as a "temporal model." According to the leader-follower model, fertility declines among highly educated women, and then less educated women follow their example. As the fertility decline begins, the gap in fertility widens between the higher and lower educational groups. These educational differentials then diminish as the transition progresses. Due to the staggered diffusion process, fertility behaviors gradually become similar across educational groups. Thus, fertility differentials by level of education are considered transient in this model (Cleland 2002). The underlying assumption is that innovations such as the norm of a small family size and the use of birth control emerge among an elite group and then are diffused across the social strata. 
In contrast, the permanent-difference model posits that educational differentials remain significant throughout the transition. This model, which builds on the microeconomic perspective that fertility is influenced by socioeconomic conditions (e.g., Becker 1981), sees the fertility decline as an adaptation to changes in the economic and the social structures (Carlsson 1966; Davis 1945; Notestein 1953). In this model, falling fertility is largely attributable to socioeconomic changes. A rise in educational attainment directly contributes to a fertility decline when the negative association between fertility and education remains constant. As a result, the fertility differentials by education persist at the end of the transition, even though the overall fertility rate decreases while the overall level of education increases.

The two models described above are essentially hypothetical and represent extreme cases. In reality, most cases fall between these two extremes because education is not only a primary determinant of fertility; it also functions as a pathway for the transmission of social norms and behaviors. The ways in which education influences fertility are so numerous (see Cleland 2002 for a comprehensive review) that structural effects alone cannot explain contemporary fertility decline. For the same reason, the indirect educational effects on fertility may be much greater than expected (Caldwell 1980). The literature also suggests that any efforts to explain the decline in fertility over the course of the transition should take into account both structural and diffusion effects (Bras 2014; Casterline 2001; Cleland 2001). Interestingly, scholars disagree about which model is empirically supported and how the fertility differentials end (James, Skirbekk, and Bavel 2012; Jeffery and Basu 1996; Lutz and Goujon 2001). For instance, Cleland (2002) argued that in most societies fertility differentials by education should shrink over time and converge at the end of the transition. He thus favored the leader-follower model (the "temporal" model in his terminology). By contrast, Bongaarts (2003), concluded based on his own analysis that the permanent-difference model is more supported because fertility differentials by education usually remain significant even in post-transitional countries.

These theoretical considerations regarding the changes in educational differentials in fertility have, however, rarely been tested. While the research described above examined several countries in late- and post-transitional phases, these studies focused primarily on less developed countries and relied on period measures of fertility (Bongaarts 2003, 2010; Cleland 2002). The mixed conclusions of these scholars may be attributable to the lack of evidence of a pattern of fertility differentials over the entire course of the transition, especially in the post-transitional phases. The literature has suggested that different patterns of fertility differentials appear in different phases of the transition. For instance, despite the inverse relationship between fertility and education, the size of fertility differentials by education tends to decline in late-transitional societies. (Bongaarts 2010; Castro Martín 1995; Chackiel and Schkolnik 1996; Shapiro 
2012). Similarly, Skirbekk (2008) found that fertility differentials across social strata become smaller as fertility gets closer to replacement level, although women's education has historically had a negative relationship with fertility.

Fertility differentials by education may vary in developed countries. For instance, in Nordic countries the inverse association between fertility and level of education has substantially weakened among recent cohorts (Kravdal and Rindfuss 2008), and is often reversed when the age at childbearing is controlled for (Andersson et al. 2009). The evidence from Nordic countries contradicts the permanent-difference hypothesis, and also clearly demonstrates that the existing theory is insufficient to cover all kinds of educational differentials in fertility. Prior research seems to have overlooked the new demographic changes that occur in countries in the post-transitional stages, or in the "Second Demographic Transition" (Lesthaeghe 2010; Lesthaeghe and van de Kaa 1986). As period fertility rates drop below the replacement level, the fertility differences by level of education decrease in absolute value. Contraceptives, which are used to explain fertility differentials by social strata, are readily available in most developed countries. However, economic recession and labor market insecurity tend to prevent young women from having large families. As a result, the fertility differentials by level of education in developed countries may be marginal or smaller than previous studies have predicted.

It is not clear whether the negative association between education and fertility diminishes or becomes reversed in the late and post-transitional stages, but it is apparent that the intensity of the association changes over the fertility transition. The dynamic features of this association have so far been underexplored. In this paper, I provide empirical evidence on the dynamic changes of fertility differentials by level of education using data covering the entire period of transition from well above replacement level to well below replacement level. I assess the contribution of changes in women's educational attainment to changes in completed fertility, and demonstrate how the trend toward having fewer children was transmitted across levels of education.

\section{The fertility transition in South Korea}

As the fertility transition in Korea has been described elsewhere (e.g., Kim and Kim 2004), I will outline it only briefly here. The fertility decline in Korea can be divided into three stages: a pre-transitional stage before the 1960s, a fertility transition between 1960-1985, and a post-transitional stage since 1985. Figure 1 depicts the total fertility rate in Korea between 1970 and 2010. Fertility in Korea did not decline until the early 1960s, and during that period the total fertility rate (TFR) remained at around 6.0 or above. However, the TFR increased somewhat in the late 1950s during the baby boom 
following the Korean War (1950-1953). International aid, which included the provision of antibiotics during and after the war, significantly reduced mortality, especially among infants and children. Factors such as an increase in population density in urban areas due to an inflow of war refugees, extreme poverty, and uncertain political situations caused by the Korean War drove young urban couples to limit their family size, fueled the demand for contraceptives (Kwon 2001). Meanwhile, in the two decades after free, compulsory primary education was introduced in 1954, illiteracy was largely eradicated. (Kim 2002).

Figure 1: Total fertility rates and the number of births in South Korea, 1970-2010

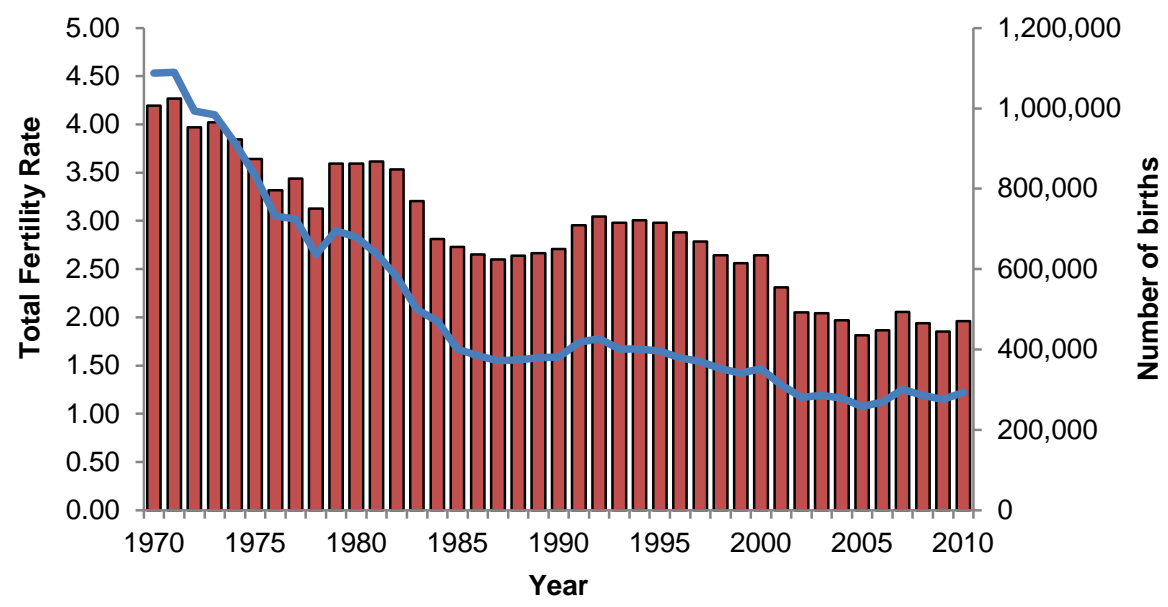

$\square$ No of births $\longrightarrow$ TFR

Source: Statistics Korea (2014).

The fertility decline started at the beginning of the 1960s. Viewing rapid population growth as a serious barrier to economic growth, the Korean government launched the National Family Planning Program in 1962 as a part of an economic development plan (for details, see Choe and Park 2006; Kwon 2001). The gross domestic product (GDP) per capita grew rapidly from \$92 in 1961 to \$1,674 in 1980 (The World Bank 2013). The aims of the family planning program were to reduce the desired family size and to promote modern contraceptive use, especially among specific 
groups of the population. The program's early focus was on reducing fertility rates among women in rural areas, where fertility was the highest and access to birth control was limited. The program was later extended to reach the poor and the factory workers in urban areas (Kwon 2001; Park et al. 1976). During this period, induced abortions were also widely performed, particularly among urban residents (Hong and Watson 1972). In the 1970s, the government used incentives to encourage a two-child family norm, such as a tax deduction and benefits for public housing for couples with one or two children (Kwon 2001).

At the same time, education about population growth was incorporated into secondary school curricula. Another factor that contributed to the fertility decline was mass internal migration from rural areas to cities. This movement was associated with rapid urbanization and industrialization, and tended to discourage childbearing as migrants struggled to adapt to city life (Lee and Farber 1984). In the 1960s and 1970s, the proportion of contraceptive users among married women quickly increased, from 16\% in 1965 to 44\% in 1976 (Kwon 2001: 47). The family planning program was successful, as slogans such as "Have fewer children and bring them up well" and "Stop at two regardless of sex" were well received by the general public. At the same time, access to secondary school education was expanding rapidly, and opportunities to pursue higher education were growing at a moderate pace (Kim 2002).

The period TFR reached the below-replacement level in 1983, and the period between 1980 and 1985 is often regarded as being the threshold for the post-transitional stage characterized by low fertility (Jun 2005; Kim 2005). Rapid economic growth continued as GDP per capita exceeded \$2,000 in 1983 and reached \$11,347 in 2000 (The World Bank 2013). In the early 1980s, the pace of fertility decline began to slow. Despite having achieved a below-replacement level of fertility, the government maintained the family planning program; encouraging families to have fewer children and seeking to mitigate son preference, partly out of fear that there would be an absolute increase in the population as the large young cohorts entered their primary childbearing ages (Lee 2009). Thus, government policies continued to promote sterilization and provide incentives for restricting family size until the late 1980s. The sustained decline in period fertility rates finally caused the government to abandon the program in the late 1980s, leaving contraceptive distribution to the private and commercial sectors. Meanwhile, unbalanced sex ratios at birth and selective abortions emerged in the 1990s after new techniques for detecting the sex of the fetus were introduced (Larsen, Chung, and Das Gupta 1998). In 1996, the government officially adopted a new population policy with an emphasis on reproductive health care services.

In 2001, the Korean period TFR reached 1.3, the lowest-low level of fertility as defined by Kohler and colleagues (2002). Since the early 1980s, access to higher education had expanded rapidly for both men and women, and women's levels of 
participation in social activities and labor have increased. More crucially, the Asian economic crisis in 1997 changed the paradigm on marriage and childbearing and augured a further decline in fertility (Kim 2009). The combination of changes in the status of women, growing economic insecurity, and insufficient childcare options led Koreans to delay marriage and childbearing (Jun 2005; Kim 2005; Suzuki 2005). In 2003 the Korean government finally phased out the family planning program, which was by then more than 40 years old. A few years later, they adopted a set of pronatalistic policies aimed at helping the country prepare for a period of aging. These policies are described in the First Basic Planning for Low Fertility and Aged Society 2006-2010, published in 2006 (Lee 2009). Despite this shift, Korean fertility is still under the lowest-low level, with a TFR of 1.19 in 2013 (Statistics Korea 2014).

\section{Data and methods}

\subsection{Data and measures}

This study relies on a series of sample data from the Korean Population and Household Census (hereafter, Korean census) between 1970 and 2010. The Korean census is conducted every five years by Statistics Korea. The census usually contains a short survey questionnaire on households and individuals, and in most cases includes a question on the number of children ever born. For my analysis, I decided to use questionnaires from seven of the nine censuses conducted between 1970 and 2010 (the census data for 1980 and 1995 do not contain pertinent information). Thus, the sample data were drawn from the censuses of 1970, 1975, 1985, 1990, 2000, 2005, and 2010.

I compute completed cohort fertility by averaging the children ever born to women aged 40-44. As in prior research (e.g., Frejka, Jones, and Sardon 2010), I consider ages 40-44 as the end of women's reproductive period. This age range was chosen for three main reasons: first, it reflects the census interval of five years; second, using ages 40-44 allowed me to include more recent birth cohorts in the analysis; and third, because the proportion of births to women age 45 and older is very small, the level of completed fertility does not change significantly when women are measured at ages 45-49 or 50$54{ }^{2}$ For the 1980 and 1995 censuses, in which the question of children ever born was omitted, the corresponding birth cohorts were selected at ages 45-49 from the censuses of 1985 and 2000, respectively. All of the information, including the number of children and educational attainment, is measured at ages $40-44$ unless otherwise specified. The

\footnotetext{
${ }^{2}$ Based on the data analyzed in this paper, for example, the computed completed fertility (CF) for the 1960 birth cohort is 1.89 , which is not far from the CF of 1.98 found when ages 50-54 are used for the end of women's reproductive years.
} 
questionnaire regarding the number of children ever born is retrospective, which means that the information provided may be inaccurate due to memory lapses or a failure to report children who died (Murphy 2009; Ní Bhrolcháin, Beaujouan, and Murphy 2011). In light of these concerns about the under-enumeration of children and selection caused by mortality differentials, responses from women over age 50 were excluded from the analysis. The sample size for each birth cohort ranges from a minimum of 1,389 to a maximum of 4,289.

The educational attainment of the respondents was measured using six categories: incomplete primary education, completed primary education, completed lowersecondary education, completed upper-secondary education, some college, and a bachelor's degree or higher. These categories are designed to capture the rapid educational transition in Korea, including the dramatic improvements in female education.

Like other social surveys in Korea, the census questionnaire asks only evermarried women about their pregnancy and birth histories. As a result, information on children born to women who have never been married is not available. I assumed that all of the women who had never been married by age 40-44 were childless because nonmarital births are rare in Korea, and marriage is still nearly universal for women by the time they reach the end of their reproductive period (Jones and Gubhaju 2009). Even though the proportion of nonmarital births to all births was less than $1 \%$ in the 1960 s and slightly increased to $2.1 \%$ by 2012 , nomarital births are still uncommon (Statistical Korea 2014). In addition, the data analyzed here suggest that approximately 98\% of women born between 1926 and 1970 were married by the ages of 40 to 44 . There are also 187 cases with missing values for the number of children among evermarried women aged 40-44. Because marriage and childbearing are virtually universal in Korea, childlessness may be considered shameful, and a non-response may be a way of avoiding a report of childlessness. ${ }^{3}$ Based on the assumption that the majority of the missing cases represent a non-response or avoidance by childless women at the end of their reproductive years, I classified those women as childless, and included them in my analysis in order to offset a possible underestimation of childless women. The number of these women is negligible, and their inclusion has a minimal effect on the results. Cases in which the educational attainment or the marital status were missing are simply omitted here because they made up less than $0.1 \%$ of the total sample size, and no regular pattern was found.

\footnotetext{
${ }^{3}$ To confirm, I checked household information for the missing cases. Of those cases, around $76 \%$ had no children living in the household. Approximately three-quarters of the cases with missing data in the CEB may be attributable to ever-married women with no children.
} 


\subsection{Methods and strategy}

The analysis presented here is composed of three parts. First, I review educational differentials in completed fertility over 45 single-year birth cohorts. As my interest is in fertility differences across educational groups, completed cohort fertility can be expressed as a function of education-specific completed fertility and the composition of educational attainment. Because we consider only women at the end of their reproductive periods, age is not required in this formula. Education-specific completed fertility rates are measured for every five-year birth cohort for women born between 1926 and 1970. The trends in education-specific completed fertility rates can be used to help us determine whether the pattern is closer to the leader-follower model or to the permanent difference model.

Second, I utilize a demographic-decomposition technique. This technique can be used to compare demographic measures between two populations or the same population between two different times, and to separate the effect of changing a single factor from other effects (Das Gupta 1993; Romo 2003). In this paper, I isolate the effects of fertility rates (rate effects) from those of educational composition (composition effects). After specifying that completed cohort fertility for a birth cohort equals the sum—as $i$ goes to $j$ (the number of educational groups) —of the educationspecific fertility rate multiplied by the proportion of the corresponding educational group, the difference in completed fertility between the two birth cohorts is decomposed into change in the rates of completed fertility and change in the composition of educational attainment as follows:

$$
\begin{gathered}
C F^{a}=\sum_{i}^{j}\left(r_{i}^{a} \cdot p_{i}^{a}\right) \\
\Delta C F=C F^{a}-C F^{b}=\sum_{i}^{j}\left(r_{i}^{a} \cdot p_{i}^{a}\right)-\sum_{i}^{j}\left(r_{i}^{b} \cdot p_{i}^{b}\right)
\end{gathered}
$$

In this equation, $C F^{a}$ represents the completed cohort fertility for the birth cohort $a, \triangle C F$ is the change in completed cohort fertility between birth cohort $a$ and $b$, $i$ is the educational-level index, $j$ is the number of educational levels, $r_{i}^{a}$ is the completed fertility rate of group $i$ for the birth cohort $a$, and $p_{i}^{a}$ is the proportion of group $i$ for the birth cohort $a$.

If we have two populations, we can evaluate the effect of a single factor on a standard population, which is acquired by averaging the other factor across both populations. However, the standardizing process is much more complicated when we have multiple populations. Das Gupta (1993) suggested a useful way to standardize demographic measures for multiple populations. His technique has frequently been used 
in prior research, particularly when demographic trends have been analyzed (DeLeone, Lichter, and Strawderman 2009; Hayford 2005; Smith, Morgan, and Koropeckyj-Cox 1996). Having nine different birth cohorts, I employ Das Gupta’s method to standardize completed fertility for multiple populations, and then break it down into six educational categories. ${ }^{4}$

Finally, I use parity progression ratios to show the pattern of declining fertility across levels of education. A parity progression ratio is a demographic measure used to capture the proportion of women who have another child (parity $k+1$ ) from a certain number of children (parity k) (Preston, Heuveline, and Guillot 2001: 101-106). Parity progression ratios are simply parity-specific birth probabilities. Period parity progression ratios have often been used in prior research on fertility change (e.g., Feeney 1991). However, I use cohort parity progression ratios instead of period ratios, and further expand my calculation by the level of educational attainment in order to compare the trend of falling fertility across social strata:

$$
P P R_{(k, k+1)}=\frac{\text { Number of women at parity } k+1 \text { or more }}{\text { Number of women at parity } k \text { or more }} .
$$

I compute cohort parity progression ratios for six educational groups and compare the patterns. After parity progression ratios are used to reveal the detailed pattern of fertility decline by birth parity, we are better able to compare changes in fertility outcomes across educational groups, and thus to discern the evolutionary pattern of educational differentials in fertility. Because of the small sample size for each educational group, especially among the oldest and youngest birth cohorts, I use a fiveyear birth cohort instead of a single-year cohort for the decomposition and the parity progression ratios.

\section{Results}

\subsection{Completed fertility and educational fertility differentials}

Figure 2 shows trends in educational attainment among women aged 40-44 for the corresponding 1926-1970 birth cohorts. The figure illustrates the marked expansion in women's educational attainment between the 1926 and 1970 birth cohorts. For example, less than 5\% of women born in 1926 had more than an upper-secondary education, compared with nearly $95 \%$ of women born in 1970. Similarly, the share of

\footnotetext{
${ }^{4}$ The process of decomposing differences for polytomous-categorical variables is explained in Chevan and Sutherland (2009).
} 
women who achieved some type of higher education increased from less than $1 \%$ to $37 \%$ between two birth cohorts.

Figure 2: Compositional change in the educational attainment of women aged 40-44 for the 1926-1970 birth cohorts, South Korea

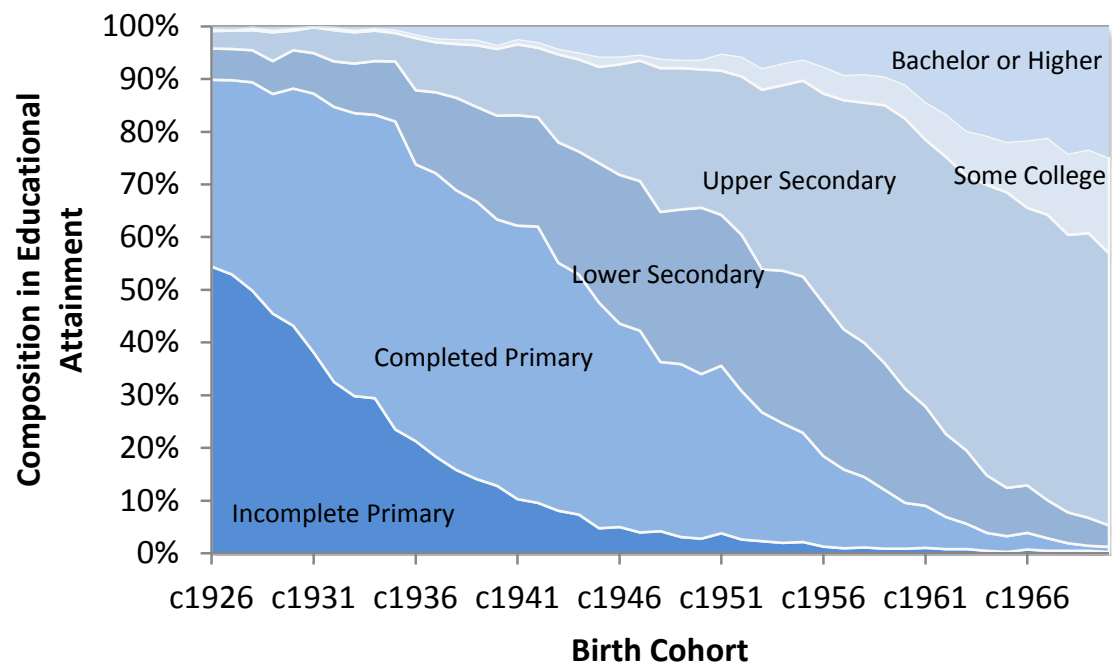

Note: Author's own calculations from Korean census sample data between 1970 and 2010.

Figure 3 illustrates the completed cohort fertility and educational differentials for women born between 1926 and 1970. There is a clear downward trend without temporal fluctuations in completed fertility among all of the cohorts. The average number of children per woman decreased by more than one-third over the 45 birth cohorts, from 5.51 for the 1926 cohort to 1.73 for the 1970 cohort. The below-replacement level was reached when the 1957 birth cohort had 1.98 births per woman. The pace of the decline in completed fertility moderated after this point, but continued through to the most recent cohort. As was mentioned previously, the period TFR of Korea fell to replacement level between 1980 and 1985 (Jun 2005; Kim 2005). For the 1957 cohort of women, who would have started having children soon after marrying, the median age at first marriage was 23 (Table A1). If we assume that the primary childbearing ages of the 1957 were 23-27, we can see that there was a shift in both the cohort and the period fertility measures at this time, which was the point in the fertility transition at which 
Korea started moving toward low fertility. The uninterrupted downward trend in completed fertility contrasts with the falling trend with fluctuations in period TFR shown in Figure 1. The trends look different because of the distinctive attributes of period TFR, which is overly sensitive to changes in the timing of fertility. For instance, the median age at first marriage was 18 among women born in 1926, but it increased to 25 among women born in 1970, and to 29 among women born in 1980 (Table A1). In the Korean context, in which marriage is universal, these shifts in the timing of marriage are closely connected to shifts in the timing of fertility. This pattern produces a tempo effect that results in an underestimation of period fertility rates (Bongaarts and Feeney 1998).

\section{Figure 3: Educational differentials in completed cohort fertility for women born between 1926 and 1970, South Korea}

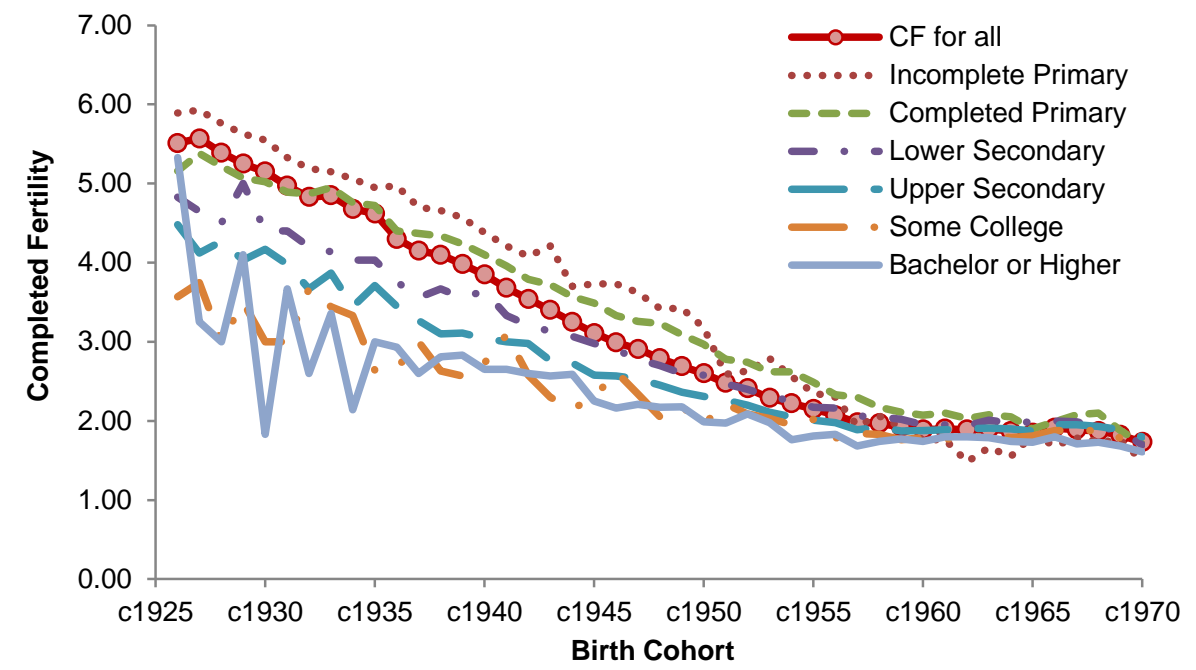

Note: Author's calculations from Korean census sample data between 1970 and 2010.

Figure 3 also displays the educational differentials in completed fertility and how they change over time. In the figure, the education-specific completed fertility shows that, by and large, women's educational attainment is negatively associated with completed fertility: the higher a woman's educational level, the fewer children she has. The fluctuations among women with both some college and more than a bachelor's 
degree among the oldest cohorts, and among women with an incomplete primary education among the youngest cohorts, are largely due to the small sample sizes.

Overall, the completed cohort fertilities for all of the educational groups declined across the 1926 and 1970 cohorts in Korea. Despite some variation in the slope across the levels of education, it is evident that a sharp fall in fertility took place among women at all educational levels. The group with the lowest level of education-i.e., an incomplete primary education-experienced the largest decline in fertility, from 5.89 for the 1926 cohort to 1.50 for the 1970 cohort.

Meanwhile, the educational differentials in completed fertility almost disappeared among recent birth cohorts with sub-replacement fertility. When we use five-year birth cohorts to mitigate temporal fluctuations between cohorts, we find that the difference between the highest and lowest fertility groups was 2.44 (42\% relative difference) among the 1926-1930 cohort, but that this gap shrank to 0.29 (14\% relative difference) among the latest 1966-1970 cohort. The lines for education-specific fertility rates have converged below the replacement level at between 1.7 and 2.0. These findings are surprising given that previous studies have argued that educational differentials in fertility remain significant even in post-transitional societies (Bongaarts 2003). Despite the unprecedented expansion in women's education in Korea, fertility differentials by level of education have faded considerably across the 45 single-year cohorts studied.

The analysis shows that, among the youngest birth cohorts, the two extreme ends of the educational spectrum-i.e., the highest and the lowest educational groups-had the lowest fertility levels. Interestingly, the least-educated women born in 1926, or those with incomplete primary education, had on average the highest number of children; while the least-educated women born in 1970 had the second-lowest number of children. Meanwhile, women with a bachelor's degree or higher had some of the lowest fertility rates across the cohorts. The lower fertility of both groups among the recent birth cohorts is attributable in part to a recent rise in never-married women in those groups. When the 1966-1970 cohorts reached ages 40-44 in 2010 (Statistics Korea 2014), the proportions of women who had never married was $25.3 \%$ among those with an incomplete primary education and 9.3\% among those with a bachelor's degree or higher. These shares were higher than the proportion of the entire 1966-1970 cohort who had never married (6.2\%), and were far higher than that of the 1926-1930 cohort $(0.4 \%$ in 1970$)$. A possible explanation for these trends is that when primary school completion is mandatory, women with an incomplete primary education are more likely to be socially disadvantaged or physically/mentally disabled, and would therefore have difficulties finding an appropriate partner. Meanwhile, as the age at first marriage rose steadily, the share of women who remained single through the end of the reproductive span gradually increased, especially among those with the most education. 


\subsection{Was the fertility decline in Korea driven by educational expansion?}

Table 1 shows the change in completed cohort fertility and its decomposition results for five-year birth cohorts. The bottom section of the table provides a comparison between the oldest and youngest birth cohorts. Due to small sample sizes, five-year birth cohorts are used instead of single-year birth cohorts.

Table 1: Standardization and decomposition of the change in completed fertility between the 1926-1930 and 1966-1970 birth cohorts

\begin{tabular}{|c|c|c|c|c|c|c|c|c|c|}
\hline \multicolumn{10}{|c|}{ A. Standardization and decomposition of change in completed fertility } \\
\hline \multirow[t]{2}{*}{ Birth cohort } & \multirow[t]{2}{*}{ CF } & \multicolumn{2}{|c|}{ CF standardized except } & \multirow{2}{*}{\multicolumn{2}{|c|}{ Observed change in CF }} & \multicolumn{4}{|c|}{ Change attributable to } \\
\hline & & $\begin{array}{l}\text { Fertility } \\
\text { rates }\end{array}$ & $\begin{array}{l}\text { Educational } \\
\text { composition }\end{array}$ & & & \multicolumn{2}{|c|}{ Rate effects } & \multicolumn{2}{|c|}{ Composition effects } \\
\hline C1926-1930 & 5.36 & 4.83 & 3.49 & & & & & & \\
\hline C1931-1935 & 4.78 & 4.34 & 3.41 & -0.58 & $(100 \%)$ & -0.49 & $(85 \%)$ & -0.09 & $(15 \%)$ \\
\hline C1936-1940 & 4.07 & 3.79 & 3.25 & -0.71 & $(100 \%)$ & -0.55 & $(78 \%)$ & -0.16 & $(22 \%)$ \\
\hline C1941-1945 & 3.41 & 3.26 & 3.11 & -0.66 & $(100 \%)$ & -0.52 & $(79 \%)$ & -0.14 & $(21 \%)$ \\
\hline C1946-1950 & 2.79 & 2.79 & 2.97 & -0.62 & $(100 \%)$ & -0.48 & $(77 \%)$ & -0.14 & $(23 \%)$ \\
\hline C1951-1955 & 2.29 & 2.35 & 2.91 & -0.50 & $(100 \%)$ & -0.44 & (88\%) & -0.06 & $(12 \%)$ \\
\hline C1956-1960 & 1.96 & 2.08 & 2.85 & -0.33 & $(100 \%)$ & -0.27 & $(81 \%)$ & -0.06 & $(19 \%)$ \\
\hline C1961-1965 & 1.88 & 2.04 & 2.80 & -0.09 & $(100 \%)$ & -0.04 & $(42 \%)$ & -0.05 & $(58 \%)$ \\
\hline C1966-1970 & 1.84 & 2.05 & 2.75 & -0.04 & $(100 \%)$ & 0.01 & $(-31 \%)$ & -0.05 & (131\%) \\
\hline \multicolumn{10}{|c|}{ B. Decomposition of change in CF between the oldest (c1926-1930) and youngest (c1966-1970) cohorts } \\
\hline \multirow{2}{*}{\multicolumn{3}{|c|}{ Birth cohort (by level of education) }} & Observed & \multirow{2}{*}{\multicolumn{2}{|c|}{ Change in standardized CF* }} & \multicolumn{4}{|c|}{ Change attributable to } \\
\hline & & & CF & & & \multicolumn{2}{|c|}{ Rate effects } & \multicolumn{2}{|c|}{ Composition effects } \\
\hline \multicolumn{3}{|c|}{ C1926-1930 / c1966-1970 } & -3.52 & -3.52 & $(100 \%)$ & -2.78 & $(79 \%)$ & -0.74 & $(21 \%)$ \\
\hline \multicolumn{3}{|c|}{ Incomplete primary } & & -2.80 & $(80 \%)$ & -0.82 & $(23 \%)$ & -1.98 & $(56 \%)$ \\
\hline \multicolumn{3}{|c|}{ Completed primary } & & -2.03 & $(57 \%)$ & -0.86 & $(24 \%)$ & -1.17 & $(33 \%)$ \\
\hline \multicolumn{3}{|c|}{ Lower secondary } & & -0.18 & $(5 \%)$ & -0.33 & (9\%) & 0.15 & $(-4 \%)$ \\
\hline \multicolumn{3}{|c|}{ Upper secondary } & & 0.84 & $(-24 \%)$ & -0.55 & $(16 \%)$ & 1.39 & $(-40 \%)$ \\
\hline \multicolumn{3}{|l|}{ Some college } & & 0.27 & $(-8 \%)$ & -0.08 & $(2 \%)$ & 0.34 & $(-10 \%)$ \\
\hline \multicolumn{4}{|c|}{ Bachelor's degree or higher or more } & 0.38 & $(-11 \%)$ & -0.15 & $(4 \%)$ & 0.53 & $(-15 \%)$ \\
\hline
\end{tabular}

Note: * For the six educational categories, standardized CFs for component were used.

While completed fertility declined continuously from the 1926-1930 cohorts to the 1966-1970 cohorts, both the rate effects and the composition effects changed in different directions. Rate effects accounted for about four-fifths of the observed changes in fertility between the cohorts until the 1956-1960 birth cohort. The rate effects over the fertility change declined for the 1961-1965 cohort, and finally began operating in 
the opposite direction for the most recent cohorts (-31\% for the 1966-1970 birth cohort). In contrast, composition effects accounted for about one-fifth of the decline in fertility for most of the birth cohorts, but the contribution of the composition effects to fertility decline soared among the most recent birth cohorts with sub-replacement fertility. Although the observed change in fertility is small, the compositional change among the 1966-1970 cohort covers more than just the fertility difference from the previous cohort.

Section B at the bottom of Table 1 summarizes the results of the decomposition of the change in completed fertility between the 1926-1930 cohort and the 1966-1970 cohort, and their extension for the six educational categories based on compositionstandardized completed fertility. The results reveal that four-fifths (79\%) of the change in completed fertility (-3.52 per woman) between the 1926-1930 and 1966-1970 cohorts was attributable to changes in fertility behaviors (rate effects), and that the expansion of women's education accounted for one-fifth (21\%) of the change. Dividing the decomposition into educational categories demonstrates how each group contributed to the change in fertility in terms of rate and composition effects. When it comes to rate effects, the contributions of the lower educational groups were especially pronounced. For instance, the changes in the fertility rates of women with incomplete or completed primary education accounted for $23 \%$ or $24 \%$, respectively, of the fertility change that occurred between the 1926-1930 and 1966-1970 cohorts. The group of women with upper-secondary education accounted for $16 \%$ of the fertility changes between these cohorts. However, the contribution to falling fertility of the rate effects of women with higher education remained marginal: $2 \%$ for women with some college and $4 \%$ for women with a bachelor's degree or higher.

The composition effects by level of education were more dynamic. The composition effect of incomplete primary education alone explained $56 \%$ of the overall change in fertility; this effect is the largest of all of the rate and composition effects by level of education. Similarly, the compositional change in completed primary education was responsible for $33 \%$ of the entire change in fertility. The bulk of the composition effects among the lower educational groups may be attributed to free, compulsory primary education. These large composition effects were, however, offset to a considerable extent by those of more educated groups which operated in the opposite direction (40\% for upper-secondary education, $10 \%$ for some college, and $15 \%$ for a bachelor's degree or higher). Such composition effects indicate that the rapid improvements in women's educational attainment levels achieved in Korea did not necessarily involve a corresponding drop in fertility when rate effects were controlled for. Specifically, the composition effects caused by a decrease in the proportion of the less-educated group were canceled out by the opposite effects caused by a subsequent rise in the shares of groups with the next-highest educational levels (not shown here). 
Despite the impressive gains made in women's educational attainment, composition effects were found to account for just one-fifth of the entire fertility change during the analyzed interval.

When we looked at rate effects and composition effects combined, it became clear that the two groups with the lowest educational levels-i.e., incomplete and completed primary education - were mainly responsible for the fertility change. The sum of the rate and composition effects for the two groups was large enough to cover the entire fertility decline. The substantial declines in fertility among the two groups also contributed to the narrowing of the fertility gaps across levels of education among the younger cohorts.

Meanwhile, completed fertility fell below the replacement level among the 19561960 cohort. Thereafter, the distribution of both the rate and the composition effects changed, and became different from that of prior birth cohorts. The cohorts of women born after 1960 were the first generation who benefited from the expansion of higher education in the early 1980s. The shift in the pattern of rate and composition effects after the 1961-1965 cohort suggests that Korea had entered the Second Demographic Transition.

The average number of children per woman declined by as much as 3.52 between the 1926-1930 and the 1966-1970 cohorts, and the majority of that change was attributable to changes in fertility behaviors. Despite the marked transition in women's educational attainment in South Korea, and contrary to expectations, we found that educational expansion accounted for only one-fifth of the fertility decline between the 1926-1930 and the 1966-1970 cohorts, or a drop in completed fertility of 0.74 children per woman. The considerable composition effects of the lower educational groups on falling fertility were offset by the opposite effects due to subsequent growth in the higher educational groups. Therefore, it is difficult to conclude that the expansion of women's educational attainment was the main driver of the fertility decline during the Korean fertility transition.

\subsection{Can a leader-follower model explain the fertility decline in South Korea?}

As can be seen in Figure 3, fertility rates by level of education are converging. The literature has suggested that this kind of convergence generally occurs when falling fertility spreads successively from leader to follower (Bongaarts 2003; Cleland 2002). Figure 3 does not provide clear evidence of whether the pattern is close to the leaderfollower model. To explore this pattern in more depth, I present cohort parity progression ratios in Figure 4. Some of the progression lines were omitted due to the small sample size. In the figure, parity progression rates to parity three (PPR2) and 
parity four (PPR3) fell considerably for all of the educational levels for the analyzed birth cohorts, while progression rates to parity one (PPR0) and to parity two (PPR1) changed little. These changes suggest that the fertility decline in Korea was mainly attributable to the transition from having four or more children to having two children.

Figure 4: Cohort parity-progression ratios by the level of women's educational attainment between the 1926-1930 and 1966-1970 birth cohorts, South Korea

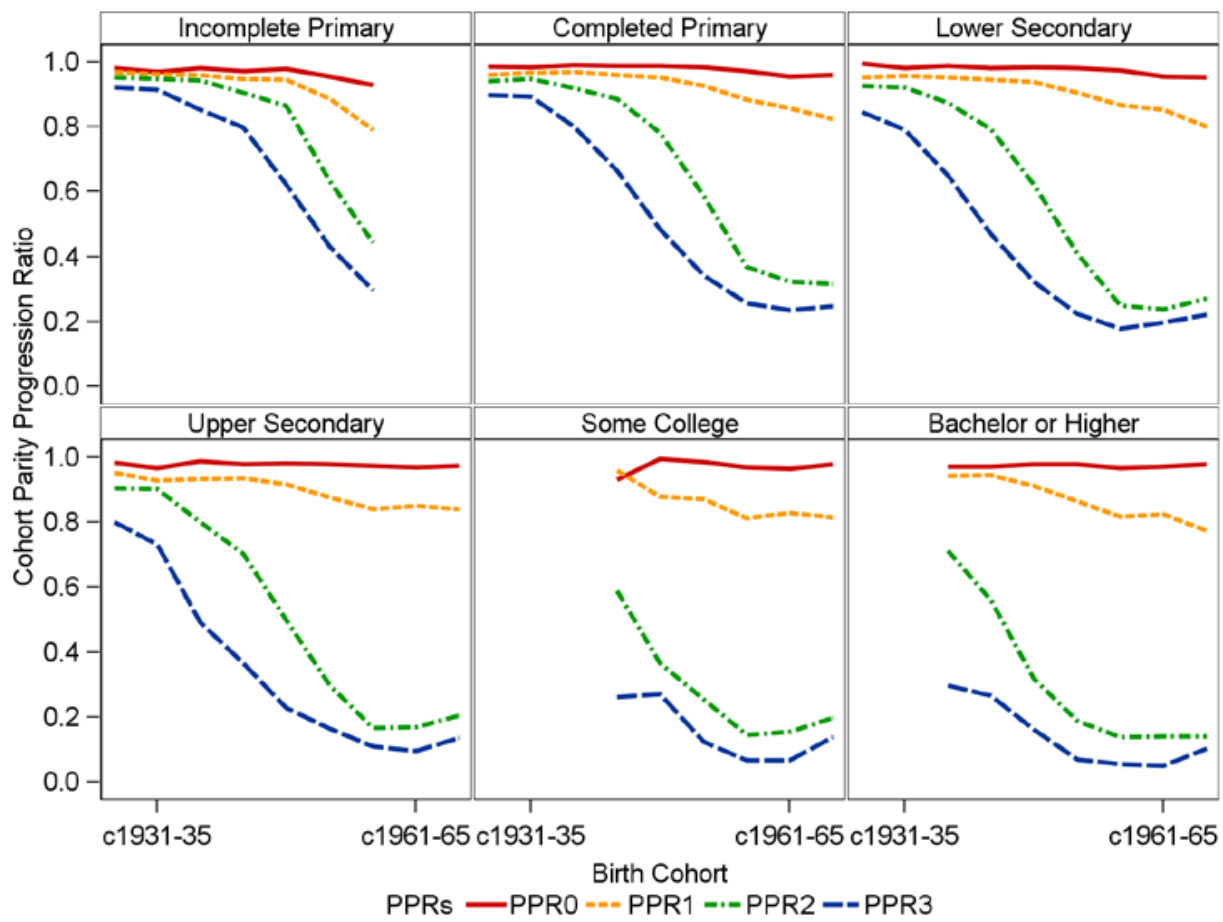

Note: In cases in which an educational group represents less than $1 \%$ of the samples for the corresponding cohort, the parity progression ratios for the group were omitted in the figure above. Author's calculations from Korean census sample data between 1970 and 2010 .

The salient feature of the figure is that education-specific patterns of parity progression represent the stages in the progression of the fertility transition. For example, the shapes of the parity progression ratios for the middle levels of education- 
i.e., lower- and upper-secondary education-are similar to those of the entire Korean population in the transition from high to low parities: the progression rates to third and fourth births declined considerably, while the progression rates to first and second births remained stable (Choe and Retherford 2009). Interestingly, the pattern of parity progression ratios for incomplete primary education is also analogous to the beginning stage of the transition, when the shift from high to low parities began. In contrast, the patterns for a bachelor's degree or a higher education seem to indicate the start of a post-transitional stage or of a new set of demographic patterns (the Second Demographic Transition); the progressions to third and fourth births stabilized at low levels, and the progression to a second birth began to decline in recent cohorts. Overall, the figure indicates that the pattern of falling parity progression ratios first began among the most educated group (bachelor's degree or higher) and soon started to take hold among the group with the next-highest level of education. This sequential decline in parity progression, which is consistent with prior research (Cleland 2002), provides evidence that lower fertility spread from highly educated women (forerunners) to less educated women (followers) during the fertility transition in Korea.

The decline in progression ratios to third-parity births (PPR2) across levels of women's education is more distinctive. Falling progression ratios of third births occurred almost at the same time, but shifted from the more-educated to the lesseducated groups. Table 2 shows which birth cohorts first experienced significant declines in the progression ratio to third births by women's educational levels. Here, I chose the parity progression ratio of 0.7 for the onset of parity-specific fertility decline, and 0.4 for the loss of parity-specific predominance. Although the choice of thresholds was arbitrary to some degree, it provided a useful way to look at the changes in the fertility pattern. As we can see in Table 2, the level of education was associated with the order of the birth cohort who first experienced "significant" declines in the progression: the higher educational group experienced an earlier drop in the parity progression ratio to third births.

Although some of the groups appear to overlap when we attempt to determine which of the birth cohorts first experienced such changes, the table shows that the pattern of falling fertility progressed through educational pathways. The progression ratios to the third birth declined with each level of education. For the two mosteducated groups-i.e., some college and a bachelor's degree and higher-the progression to a third birth began to fall below 0.7 in the 1936-1940 birth cohort and reached 0.4 in the 1946-1950 birth cohort. A similar trajectory could be observed among the groups that followed: from upper secondary, to lower secondary, to completed primary, to incomplete primary education. The spread of the decrease in the progression ratio to below 0.4 was even faster than to below 0.7 , and the time lag between the educational groups declined from a 15 -year to a 10 -year cohort interval. 
However, none of the groups who experienced a parity progression ratio to second births (PPR1) fell below 0.7, except for the group with incomplete primary education. Despite substantial changes in fertility patterns, the progression to a first and a second birth have been consistently maintained by the majority of women, which implies that a two-child family norm has been well established in Korea. For those with incomplete primary education, the parity progression ratio to parity two reached 0.7 among the 1961-1965 cohort, but its impact on the overall trend can be ignored because the corresponding cohorts came from generations in which free, compulsory primary education had been instituted (less than $1 \%$ of the cohorts).

Table 2: The first birth cohort reached below 0.7 or 0.4 of parity progression ratios by level of women's educational attainment

\begin{tabular}{lcc}
\hline & \multicolumn{2}{c}{ Parity progression ratio to third births (PPR2) } \\
\cline { 2 - 3 } Level of education & below 0.7 & below 0.4 \\
\hline Incomplete primary & $\mathrm{c} 1951-1955$ & $\mathrm{c} 1956-1960$ \\
Completed primary & $\mathrm{c} 1951-1955$ & $\mathrm{c} 1956-1960$ \\
Lower secondary & $\mathrm{c} 1946-1950$ & $\mathrm{c} 1951-1955$ \\
Upper secondary & $\mathrm{c} 1941-1945$ & $\mathrm{c} 1951-1955$ \\
Some college & $\mathrm{c} 1936-1940$ & $\mathrm{c} 1946-1950$ \\
Bachelor's degree or higher & $\mathrm{c} 1936-1940$ & $\mathrm{c} 1946-1950$ \\
\hline
\end{tabular}

Note: Author's calculations from Korean census sample data between 1970 and 2010.

The results of the cohort parity progression analysis offer evidence that the pattern of the Korean fertility transition most closely conforms to the leader-follower model. Although fertility fell in all of the educational groups with a small variation in birth cohorts, the decline definitely spread from the most- to the least-educated groups. In addition, despite the sustained low fertility in Korea, the two-child family norm seems to be firmly established in all of the educational groups, and the tendency to have a third child has declined considerably during the transition. This striking transformation in parity progression patterns was completed in just 40 years of birth cohorts. 


\section{Conclusions and discussion}

South Korea experienced one of the most rapid declines in fertility of any country in the late 20th century. The aim of this paper was to identify how educational differentials in fertility changed over the Korean fertility transition, and to understand the contribution of changes in educational attainment to the fertility decline among women born between 1926 and 1970.

Completed fertility declined from 5.51 for women born in 1926 to 1.73 for women born in 1970. Educational differentials in completed fertility have gradually decreased. Although marginal differences still remain, the once-obvious gaps in lifetime fertility by level of education disappeared among the birth cohorts of women who just ended their reproductive periods. In the recent cohorts, women at both extremes of the educational spectrum had the lowest levels of completed fertility. This finding blurs the negative association between fertility and women's education that was clearly observed in the early stages of the transition. Overall, educational differentials in completed fertility faded away as the transition reached its end. This convergence of educational differentials in fertility is surprising because it contradicts previous research showing that the fertility gaps between educational groups are substantial in most societies, even those in the end- or post-transitional stage (Abbasi-Shavazi et al. 2008; Alves and Cavenaghi 2009; Bongaarts 2003, 2010).

The extraordinary decline in fertility in Korea was mainly attributable to decreasing fertility in every social group for the cohorts who were having children prior to the point when the replacement level was reached. Women's educational attainment did not start to play a large role in fertility changes until after this point. While the rapid increase in women's educational attainment was virtually unprecedented, it still only accounted for one-fifth of the fertility decline during the transition in Korea. The pattern of fertility differentials by level of education in Korea appears to have conformed with the leader-follower model rather than with the permanent-difference model (Bongaarts 2003; Cleland 2002). Having experienced more rapid fertility decline, the Korean pattern could be identified through cohort parity progression ratios by level of education. The trends in parity progression ratios demonstrate that the decline in fertility spread from the most-educated to the least-educated groups during the fertility transition, and that the norm of a two-child family became established across all social strata in Korea. Such a rapid transformation of fertility patterns cannot occur without the extensive diffusion and social interactions of small family norms and contraceptive use, as prior research has discussed (Chung and Das Gupta 2007; Kye 2012; Montgomery and Chung 1999).

Differences in rates of diffusion and social interactions may lead to further variation in the dynamic pattern of educational differentials in fertility across countries 
(Bongaarts 2003). For instance, family planning programs can reduce the fertility gap across social strata by helping to meet the contraceptive needs of disadvantaged women (Amaral and Potter 2009). In Korea, the family planning program was initially targeted at women in rural areas with high fertility rates and limited access to birth control (Kwon 2001). As the result of active fieldwork and campaigns, contraceptive use and the small family norm spread from one group to another (Montgomery and Chung 1999; Park et al. 1976). In countries in the late-transitional stages, in which most of the differences in fertility rates come from differences in rates of unwanted pregnancies (Bongaarts 2003, 2010), family planning programs may be more useful than is generally expected in narrowing the fertility gap across social strata. Without such efforts, fertility differentials by social strata may remain significant even after countries lower their overall fertility to replacement levels, as in the case in Brazil (Alves and Cavenaghi 2009; Lam and Duryea 1999).

For the same reason, the degree of homogeneity in a society could influence the extent of fertility differentials. Innovative ideas and behaviors may spread more quickly in a homogenous society than in a heterogeneous society once the adoption of the innovation reaches a certain threshold. Located on a small peninsula in which the land route north has long been closed by the political conflict with North Korea, South Korea is an ethnically homogenous society with a single language. Having a relatively homogenous culture and geographic constraints likely facilitates social interaction and the diffusion of innovative ideas and behaviors in Korea. Thus, the Korean pattern of educational differentials in fertility may differ from the patterns found in other countries.

Internal migration might have contributed to the converging patterns of fertility differentials. Industrialization and urbanization triggered large-scale internal migrations from rural to urban areas between the 1960s and 1980s in Korea. Internal migrants from rural areas contributed to the decline in fertility through their acceptance of contraceptive use and the small family norm (Lee and Farber 1984; Lee and Pol 1993). However, because most of the people affected by this trend were from birth cohorts involved in the early phases of the transition, internal migration probably did not play an important role in the overall pattern of fertility differentials.

When interpreting the results of this study, several points should be noted. First, these findings should be differentiated from research based on period fertility. Cohort fertility measured at the end of the reproductive span is usually less responsive than period fertility in reflecting the dynamic changes in fertility at younger ages. Although completed cohort fertility may mask qualitative aspects of fertility behaviors, such as birth timing and birth spacing, it is relatively stable and precise. By contrast, period measures of fertility may present a distorted picture, especially when the timing of childbearing changes as rapidly as it did in Korea (Bongaarts and Feeney 1998). 
Second, the findings do not indicate that improvements in women's educational attainment are not a necessary prerequisite for fertility decline. My analysis showed that a considerable portion of the fertility decline was attributable to compositional changes in the lower educational groups, caused by the introduction of universal primary education. In addition, education helped to spread new ideas and values. This paper supports the hypothesis that mass education provides a solid foundation for fertility decline in both direct and indirect ways, and that the indirect effects of education on fertility are greater than the direct effects (Axinn and Barber 2001; Caldwell 1980).

This study also has a few limitations. First, I could not use detailed information on fertility other than number of children ever born. Educational differentials in completed fertility can be further decomposed into differences in wanted and unwanted fertility, and their contributions to fertility differentials also vary with the stages of the transition (Bongaarts 2003; Musick et al. 2009). Once better data become available, decomposing the fertility difference and how it changes over time would be an interesting topic. Second, the completed fertility rates used here may have been marginally underestimated due to data limitations, although this did not appear to make a meaningful difference in the results. With the data for Korea that are currently available, it is difficult to estimate the exact levels of fertility for women with nontraditional childbearing histories, such as those who had out-of-wedlock births or are childless. Finally, as the information on children ever born comes from retrospective questions, the number may be underestimated due to incorrect recall or the omission of children who died.

Despite these shortcomings, this paper provides a rare look at how educational differentials in fertility change in a country that has experienced a rapid decline in fertility as part of a fertility transition. In Korea, the sustained low fertility has brought on social concerns in recent years. However, looking at cohort fertility rather than period fertility, raises the question of whether or not the Korean fertility has reached the lowest-low level. Researchers and policy-makers should pay more attention to the timing of fertility inherent in period fertility, especially in countries where the ages at childbearing change as rapidly as they have been in Korea (Bongaarts and Feeney 1998). The effects of education on fertility decline are diverse and vary according to the conditions of each country. The Korean pattern of educational differentials in fertility illustrates the need for a more comprehensive investigation of the relationship between education and fertility transitions. 


\section{Acknowledgements}

The early stage of this research was conducted during the 2012 Young Scientist Summer Program (YSSP) at the International Institute of Applied System Analysis (IIASA), Laxenburg, Austria. The author gratefully acknowledges the Nathan Keyfitz fellowship, which provided funding to participate in the 2012 YSSP at IIASA. The author thanks Bilal Barakat and Tomáš Sobotka for their excellent supervision and the World Population team for their useful comments. An earlier version of this paper was presented at the YSSP Late Summer Workshop 2012 at IIASA (Aug 23-24) and the Population Association of America 2013 Annual Meetings at New Orleans, LA (April 11-13). This research received support from the Office of the Vice-President for Research and Economic Affairs, the Graduate Research Support Program, and the Graduate College at Arizona State University. The author is grateful to Statistics Korea for providing data. The author also appreciates the guidance of Sarah Hayford, and thanks Victor Agadjanian, Scott Yabiku, and Doris Palmer, and two anonymous reviewers for their valuable suggestions and comments. Carol Sonenklar provided editorial help.

\section{Corrections:}

On February 25, 2015 equation (2) on page 1472 was corrected at the author's request. 


\section{References}

Abbasi-Shavazi, M.J., Lutz, W., Hosseini-Chavoshi, M., KC, S., and Nilsson, S. (2008). Education and the world's most rapid fertility decline in Iran (Report No. Interim Report IR-08-010). Laxenburg, Austria: International Institute for Applied Systems Analysis.

Alves, J.C.S. and Cavenaghi, S. (2009). Timing of childbearing in below replacement fertility regimes: how and why Brazil is different. Paper presented at the XXVI IUSSP International Population Conference, Marrakech, Morocco, Sep 27-Oct 2 2009.

Amaral, E.F.L. and Potter, J.E. (2009). Políticas de población, programas gubernamentales y fecundidad: una comparación entre el Brasil y México. Notas de Población 87: 7-33.

Andersson, G., Rønsen, M., Knudsen, L.B., Lappegård, T., Neyer, G., Skrede, K., Teschner, K., and Vikat, A. (2009). Cohort fertility patterns in the Nordic countries. Demographic Research 20(14): 313-352. doi:10.4054/DemRes.2009. 20.14 .

Axinn, W.G. and Barber, J.S. (2001). Mass education and fertility transition. American Sociological Review 66(4): 481-505. doi:10.2307/3088919.

Becker, G.S. (1981). A Treatise on the Family. Cambridge: Harvard University Press.

Bongaarts, J. (2003). Completing the fertility transition in the developing world: The role of educational differences and fertility preferences. Population Studies 57(3): 321-335. doi:10.1080/0032472032000137835.

Bongaarts, J. (2010). The causes of educational differences in fertility in Sub-Saharan Africa. Vienna Yearbook of Population Research 8: 31-50. doi:10.1553/populati onyearbook2010s31.

Bongaarts, J. and Feeney, G. (1998). On the quantum and tempo of fertility. Population and Development Review 24(2): 271-291. doi:10.2307/2807974.

Bras, H. (2014). Structural and diffusion effects in the Dutch fertility transition, 19871940. Demographic Research 30(5): 151-186. doi:10.4054/DemRes.2014.30.5.

Caldwell, J.C. (1980). Mass education as a determinant of the timing of fertility decline. Population and Development Review 6(2): 225-255. doi:10.2307/1972729.

Caldwell, J.C. (1982). Theory of fertility decline. New York: Academic Press. 
Carlsson, G. (1966). The decline of fertility. Innovation or adjustment process. Population Studies 20(2): 149-174. doi:10.2307/2172980.

Casterline, J.B. (2001). Diffusion processes and fertility transition: Introduction. In: Casterline, J.B. (ed.). Diffusion process and fertility transition: Selected perspectives. Washington, DC: National Academy Press: 1-38.

Castro Martín, T. (1995). Women's education and fertility: results from 26 Demographic and Health Surveys. Studies in Family Planning 26(4): 187-202. doi:10.2307/2137845.

Chackiel, J. and Schkolnik, S. (1996). Latin America: Overview of the fertility transition, 1950-1990. In Guzman, J.M., Singh, S., Rodriguez, G., and Pantelides, E.A. (eds.). The Fertility Transition in Latin America. New York: Oxford University Press: 3-26.

Chevan, A. and Sutherland, M. (2009). Revisiting das gupta: Refinement and extension of standardization and decomposition. Demography 46(3): 429-449. doi:10.1353/dem.0.0060.

Choe, M.K. and Park, K.A. (2006). Fertility decline in South Korea: Forty years of policy-behavior dialogue. Korea Journal of Population Studies 29(2): 1-26.

Choe, M.K. and Retherford. R.D. (2009). The contribution of education to South Korea's fertility decline to below 'lowest-low' level. Asian Population Studies 5(3): 267-288. doi:10.1080/17441730903351503.

Chung, W. and Das Gupta, M. (2007). The decline of son preference in South Korea: The roles of development and public policy. Population and Development Review 33(4): 757-783. doi:10.1111/j.1728-4457.2007.00196.x.

Cleland, J. (2001). Potatoes and pills: An overview of innovation-diffusion contribution to explanations of fertility decline. In: Casterline, J.B. (ed.). Diffusion process and fertility transition: Selected perspectives. Washington, DC: National Academy Press: 39-65.

Cleland, J. (2002). Education and future fertility trends, with special referecne to midtransitional countries. Population Bulletin of the United Nations Special Issue(48/49): 183-194. http://www.un.org/esa/population/publications/ completingfertility/bulletin-english.pdf.

Cochrane, S.H. (1979). Fertility and education: What do we really know? Baltimore/London: The Johns Hopkins University Press for the World Bank. 
Das Gupta, P. (1993). Standardization and decomposition of rates: A user's manual. US Department of Commerce, Economics and Statistics Administration, Bureau of the Census.

Davis, K. (1945). The world demographic transition. Annals of the American Academy of Political and Social Science 237(1): 1-11. doi:10.1177/000271624523700 102.

DeLeone, F.Y., Lichter, D.T., and Strawderman, R.L. (2009). Decomposing trends in nonmarital fertility among Latinas. Perspectives on Sexual and Reproductive Health 41(3): 166-172. doi:10.1363/4116609.

Feeney, G. (1991). Fertility decline in Taiwan: A study using parity progression ratios. Demography 28(3): 467-479. doi:10.2307/2061468.

Frejka, T., Jones, G.W., and Sardon, J.P. (2010). East Asian childbearing patterns and policy developments. Population and Development Review 36(3): 579-606. doi:10.1111/j.1728-4457.2010.00347.x.

Hayford, S.R. (2005). Stable aggregate fertility in a time of family change: A decomposition of trends in American fertility, 1970-1999. Biodemography and Social Biology 52(1-2): 1-17. doi:10.1080/19485565.2002.9989096.

Hong, S.-B. and Watson, W.B. (1972). The Role of Induced Abortion in Fertility Control in Korea. Australian and New Zealand Journal of Obstetrics and Gynaecology 13: 115-120. doi:10.1111/j.1479-828X.1972.tb02340.x.

James, K.D., Skirbekk, V., and Bavel, J.V. (2012). Education and the Global Fertility Transition - Foreword. Vienna Yearbook of Population Research 10: 1-8.

Jeffery, R. and Basu, A.M. (1996). Girls' Schooling, Women's Autonomy and Fertility Change in South Asia. New Delhi: Sage.

Jejeebhoy, S.J. (1995). Women's Education, Autonomy, and Reproductive Behaviour: Experience from Developing Countries. Oxford: Clarendon Press.

Jones, G.W. and Gubhaju, B. (2009). Factors influencing changes in mean age at first marriage and proportions never marrying in the low-fertility countries of East and Southeast Asia. Asian Population Studies 5(3): 237-265. doi:10.1080/ 17441730903351487.

Jun, K.-H. (2005). The transition to sub-replacement fertility in South Korea: Implications and prospects for population policy. The Japanese Journal of Population 3(1): 26-57. 
Kim, D.-S. (2005). Theoretical explanations of rapid fertility decline in Korea. The Japanese Journal of Population 3(1): 2-25.

Kim, D.-S. (2009). The 1997 Asian Economic Crisis and Changes in the Pattern of Socioeconomic Differentials in Korean Fertility. In: Jones, G., Straughan, P.T., and Chan, A. (eds). Ultra-Low Fertility in Pacific Asia: Trends, Causes and Policy Issues. Oxon, U.K.: Routledge: 110-131.

Kim, D.-S. and Kim, C.-S. (2004). The Population of Korea. Korea National Statistical Office.

Kim, G.-J. (2002). Education policies and reform in South Korea. In: T.W.B., African Region (ed.). Secondary Education in Africa: Strategies for Renewal. Washington, DC: The World Bank: 29-40.

Kohler, H.P., Billari, F.C., and Ortega, J.A. (2002). The emergence of lowest-low fertility in Europe during the 1990s. Population and Development Review 28(4): 641-680. doi:10.1111/j.1728-4457.2002.00641.x.

Kravdal, Ø. and Rindfuss, R.R. (2008). Changing relationships between education and fertility: A study of women and men born 1940 to 1964. American Sociological Review 73(5): 854-873. doi:10.1177/000312240807300508.

Kwon, T.H. (2001). The national family planning program and fertility transition in South Korea. In: Mason, A. (ed.). Population Policies and Programs in East Asia. Hawaii: The East-West Center: 39-64.

Kye, B. (2012). Cohort Effects or Period Effects? Fertility Decline in South Korea in the Twentieth Century. Population Research and Policy Review 31: 1-29. doi:10.1007/s11113-012-9232-y.

Lam, D. and Duryea, S. (1999). Effects of schooling on fertility, labor supply, and investments in children, with evidence from Brazil. Journal of Human Resources 34(1): 160-192. doi:10.2307/146306.

Larsen, U., Chung, W., and Das Gupta, M. (1998). Fertility and son preference in Korea. Population Studies 52(3): 317-325. doi:10.1080/0032472031000150496.

Lee, B.S. and Farber, S.C. (1984). Fertility adaptation by rural-urban migrants in developing countries: The case of Korea. Population Studies 38(1): 141-155. doi:10.2307/2174360.

Lee, B.S. and Pol, L.G. (1993). The influence of rural-urban migration on migrants' fertility in Korea, Mexico and Cameroon. Population Research and Policy Review 12(1): 3-26. doi:10.1007/BF01074506. 
Lee, S.-S. (2009). Low fertility and policy responses in Korea. The Japanese Journal of Population 7(1): 57-70.

Lesthaeghe, R. (2010). The unfolding story of the Second Demographic Transition. Population and Development Review 36(2): 211-251. doi:10.1111/j.1728-4457. 2010.00328.x.

Lesthaeghe, R. and van de Kaa, D.J. (1986). Twee demografische transities ('Two demographic transitions?'. In: Lesthaeghe, R. and van de Kaa, D.J. (eds.). Bevolking: groei en krimp. Deventer: Van Loghum-Slaterus: 9-24.

Lutz, W. and Goujon, A. (2001). The World's Changing Human Capital Stock: MultiState Population Projections by Educational Attainment. Population and Development Review 27(2): 323-339. doi:10.1111/j.1728-4457.2001.00323.x.

Montgomery, M.R. and Chung, W. (1999). Social networks and the diffusion of fertility control in the Republic of Korea. In: Leete, R. (ed.). Dynamics of values in fertility change. Oxford: Oxford University Press: 179-209.

Murphy, M. (2009). Where have all the children gone? Women's reports of more childlessness at older ages than when they were younger in a large-scale continuous household survey in Britain. Population Studies 63(2): 115-133. doi:10.1080/00324720902917238.

Musick, K., England, P., Edgington, S., and Kangas, N. (2009). Education differences in intended and unintended fertility. Social Forces 88(2): 543-572. doi:10.1353/ sof.0.0278.

Notestein, F.W. (1953). Economic problems of population change. In: Proceedings of the Eight International Conference of Agricultural Economists. London: Oxford University Press.

Ní Bhrolcháin, M., Beaujouan, É., and Murphy, M. (2011). Sources of error in reported childlessness in a continuous British household survey. Population Studies 65(3): 305-318. doi:10.1080/00324728.2011.607901.

Park, H.J., Kincaid, D.L., Chung, K.K., Han, D.S., and Lee, S.B. (1976). The Korean Mothers' Club Program. Studies in Family Planning 7(10): 275-283. doi:10.2307/1966343.

Preston, S.H., Heuveline, P., and Guillot, M. (2001). Demography: Measuring and Modeling Population Processes. Oxford, England: Blackwell Publishing.

Romo, V.C. (2003). Decomposition Methods in Demography. Amsterdam, Netherlands: Rozenberg Publishers. doi:10.1353/dem.2003.0008. 
Shapiro, D. (2012). Women's education and fertility transition in sub-Saharan Africa. Vienna Yearbook of Population Research 10: 9-30. doi:10.1553/populationyear book2012s9.

Skirbekk, V. (2008). Fertility trends by social status. Demographic Research 18(5): 145-180. doi:10.4054/DemRes.2008.18.5.

Smith, H.L., Morgan, S.P., and Koropeckyj-Cox, T. (1996). A decomposition of trends in the nonmarital fertility ratios of blacks and whites in the United States, 19601992. Demography 33(2): 141-151. doi:10.2307/2061868.

Statistics, Korea (2010). Women's lives through statistics in 2010 [electronic resource]. Daejeon, South Korea: Statistics Korea. http://kosis.kr/ups/ups_01List01.jsp? pubcode=KL.

Statistics, Korea (2014). Korea Statistical Information Service [elecronic resource]. Daejeon, South Korea: Statistics Korea. http://kosis.kr/.

Suzuki, T. (2005). Why is fertility in Korea lower than in Japan? Journal of Population Problems 61(2): 23-39.

The World Bank, T.W.B. (2013). World Development Indicators [elecronic resource]. Washington, DC: World DataBank. http://databank.worldbank.org/. 


\section{Appendix}

Table A1: Median age at first marriage for women born between 1926 and 1980, South Korea

\begin{tabular}{|c|c|c|c|c|c|c|c|}
\hline Cohort & Median age & Cohort & Median age & Cohort & Median age & Cohort & Median age \\
\hline c1926 & 18 & c1940 & 22 & c1954 & 23 & c1968 & 25 \\
\hline c1927 & 18 & c1941 & 22 & c1955 & 23 & c1969 & 25 \\
\hline c1928 & 18 & c1942 & 23 & c1956 & 23 & c1970 & 25 \\
\hline c1929 & 18 & c1943 & 23 & c1957 & 23 & c1971 & 26 \\
\hline c1930 & 19 & c1944 & 23 & c1958 & 23 & c1972 & 26 \\
\hline c1931 & 19 & c1945 & 23 & c1959 & 23 & c1973 & 26 \\
\hline c1932 & 20 & c1946 & 23 & c1960 & 24 & c1974 & 27 \\
\hline c1933 & 20 & c1947 & 24 & c1961 & 24 & c1975 & 27 \\
\hline c1934 & 20 & c1948 & 24 & c1962 & 24 & c1976 & 27 \\
\hline c1935 & 20 & c1949 & 24 & c1963 & 24 & c1977 & 27 \\
\hline c1936 & 21 & c1950 & 24 & c1964 & 24 & c1978 & 28 \\
\hline c1937 & 21 & c1951 & 23 & c1965 & 25 & c1979 & 29 \\
\hline c1938 & 22 & c1952 & 23 & c1966 & 25 & c1980 & 29 \\
\hline c1939 & 22 & c1953 & 23 & c1967 & 25 & & \\
\hline
\end{tabular}

Note: Author's calculations with a life-table method, based on women's age at first marriage from the Korean census sample data of 1980, 1995, 2005, and 2010; Extra birth cohorts of women born between1971 and1980 were added to provide recent trends in the timing of marriage. 
Sam Hyun Yoo: Educational differentials in cohort fertility in South Korea 